(C) 2020, The Authors. Published by Elsevier Inc. and Fass Inc. on behalf of the American Dairy Science Association ${ }^{\circledR}$. This is an open access article under the CC BY-NC-ND license (http://creativecommons.org/licenses/by-nc-nd/4.0/).

\title{
A survey on sensor systems used in Italian dairy farms and comparison between performances of similar herds equipped or not equipped with sensors
}

\author{
I. Lora, ${ }^{1} \oplus$ F. Gottardo, ${ }^{1} \oplus$ B. Contiero, ${ }^{1} \oplus$ A. Zidi, ${ }^{1}$ L. Magrin, ${ }^{1}$ M. Cassandro, ${ }^{2} \odot$ and G. Cozzi ${ }^{1 *} \odot$ \\ ${ }^{1}$ Department of Animal Medicine, Production and Health, University of Padova, Viale dell'Università 16, Legnaro (Padova) 35020, Italy \\ ${ }^{2}$ Department of Agronomy, Food, Natural resources, Animals and Environment, University of Padova, Viale dell'Università 16, \\ Legnaro (Padova) 35020, Italy
}

\begin{abstract}
Sensor systems (SS) were developed over the last few decades to help dairy farmers manage their herds. Such systems can provide both data and alerts to several productive, behavioral, and physiological indicators on individual cows. Currently, there is still a lack of knowledge on both the proportion of dairy farms that invested in SS and type of SS installed. Additionally, it is still unclear whether the performances of herds equipped with SS differ from those of similar herds managed without any technological aid. Therefore, the aims of this study were (1) to provide an insight into SS spread among Italian dairy farms and (2) to analyze the performances of similar herds equipped or not equipped with SS. To reach the former goal, a large survey was carried out on 964 dairy farms in the northeast of Italy. Farmers were interviewed by the technicians of the regional breeders association to collect information on the type of SS installed on farms and the main parameters recorded. Overall, $42 \%$ of the surveyed farms had at least $1 \mathrm{SS}$, and most of them $(72 \%)$ reared more than 50 cows. Sensors for measuring individual cow milk yield were the most prevalent type installed ( $39 \%$ of the surveyed farms), whereas only $15 \%$ of farms had SS for estrus detection. More sophisticated parameters, such as rumination, were automatically monitored in less than $5 \%$ of the farms. To reach the latter goal of the study, a subset of 100 Holstein dairy farms with similar characteristics was selected: half of them were equipped with SS for monitoring at least individual milk yield and estrus, and the other half were managed without any SS. Average herd productive and reproductive data from official test days over $3 \mathrm{yr}$ were analyzed. The outcomes of the comparison showed that farms with SS had higher
\end{abstract}

\footnotetext{
Received November 28, 2019.

Accepted June 20, 2020.

*Corresponding author: giulio.cozzi@unipd.it
}

mature-equivalent milk production. Further clustering analysis of the same 100 farms partitioned them into 3 clusters based on herd productive and reproductive data. Results of the Chi-squared test showed that the proportion of farms equipped with SS was greater in the cluster with the best performance (e.g., higher milk yield and shorter calving interval). However, the presence of a few farms equipped with SS in the least productive cluster for the same parameters pointed out that although the installation of SS may support farmers in time- and labor-saving or in data recording, it is not a guarantee of better herd performance.

Key words: sensor system, dairy cow, survey, performance

\section{INTRODUCTION}

Over the last few decades, the European dairy sector has changed deeply, recording a significant drop in the number of dairy farms and a parallel increase in the average herd size (Barkema et al., 2015). Such an increase in dairy herd size was accompanied by the development of automated sensor systems (SS) that help farmers manage their herd and reduce labor costs (de Koning, 2010; Rutten et al., 2013). Sensor systems are electronic devices with specific software that provide information and alerts on several productive, behavioral, and physiological traits of individual cows (Rutten et al., 2013; Steeneveld and Hogeveen, 2015). The first SS were developed in the 1970s for recording individual milk yield, whereas SS for automatic estrus detection have been on the market since the 1980s (Saint-Dizier and ChastantMaillard, 2012; Mottram, 2016). More recently, a new generation of SS was developed to control cow health and behavior. Rumination, activity, BW change, and milk SCC are the main indicators recorded by these new devices, and a wide variety of SS that can record 1 or more indicators is now available on the market (Bar and Solomon, 2010; van der Tol and van der Kamp, 2010; de Koning, 2011). Currently, information from 
milk and milking period are still the main focuses of SS development, and the automatic milking systems (AMS) are the driving force for the spread of SS in dairy farms of Europe (Rutten et al., 2013). However, thanks to the use of proper algorithms, new generation SS provide a lot of additional information on individual cows that allow for more capabilities, such as the detection of alterations in cow health status (Stangaferro et al., 2016a,b,c; Steensels et al., 2016; King and DeVries, 2018). In the near future, SS are expected to be used for further innovative goals such as the development of proxies for the selection of new complex traits in dairy cattle (e.g. resilience and efficiency; Ouweltjes et al., 2019).

Despite this promising scenario, information on the diffusion and type of SS installed by dairy farmers is still very limited. Knowing which kind of data is available in the field is an essential prerequisite for carrying out new large-scale studies, as well as for developing new algorithms based on data provided by SS. Some surveys on SS diffusion among dairy farms were published in different countries (Barkema et al., 2015; Borchers and Bewley, 2015; Steeneveld and Hogeveen, 2015), but to our knowledge, Italy was never included. Moreover, it is still unclear whether herd performances of farms that invest in SS differ from those of other similarly managed farms without any technological aid. Therefore, this study primarily aimed to provide an overview on how much the use of SS has spread among Italian dairy farms, and then to investigate whether having installed SS to monitor at least individual milk yield and estrus can be associated with different herd productive or reproductive performance.

\section{MATERIALS AND METHODS}

\section{Survey on Sensor Systems Availability in Italian Dairy Farms}

A survey on SS availability in dairy farms was conducted in the eastern part of the Po Valley (Italy), from November to December 2017. The survey was carried out thanks to the collaboration with the technicians of the breeders association of the Veneto Region (ARAV), who submitted a questionnaire to their associated dairy farmers. The framework of the questionnaire and the categorization of both SS and recorded parameters were built by adapting to the national reality previous questionnaires used in similar surveys published in peer-reviewed papers (Borchers and Bewley, 2015; Steeneveld and Hogeveen, 2015).

The questionnaire was composed of 3 main sections: (1) farm description, (2) sensors for milking-linked parameters, and (3) sensors for monitoring cow behavior.
In section 1 , farmers were asked to declare farm official identification number, farm name, farm location (province and city), the overall number of cows reared, number of cows by breed type, and housing system (loose housing vs. tiestall). To make the questionnaire easier to fill in, thus reducing misinterpretation possibilities, the SS installed on-farm were divided into 2 main categories: those applied for recording milkinglinked parameters and those applied to monitor cow behavior. Therefore, in section 2, farmers were asked about their milking system (milk pipeline-tiestall, milking parlor, or AMS) and to declare whether they have any SS installed for monitoring milking-linked parameters (yes or no). In the case of a positive answer, they were asked to disclose the type of SS installed (brand and model) and the recorded parameters by choosing 1 or more options from a list of 3 main categories: (1) individual milk yield, (2) mastitis alert based either on SCC, milk conductivity, milk temperature, or other, and (3) milk quality in terms of fat and protein content. In section 3, farmers were asked to declare whether the herd was equipped with SS for monitoring any parameter of cow behavior (yes or no). If yes, they were asked to disclose the type of SS adopted by choosing among collars, pedometers, and eartags and report their brand and model. Moreover, farmers reported the recorded parameters by choosing one or more options from a list of 5 main categories: (1) estrus alert, (2) rumination, (3) visit to the manger, (4) resting, and (5) location in the barn. Open-ended questions were placed at the end of sections 2 and 3 to report for SS or measured parameters that were not included in the proposed lists.

A total of 993 questionnaires were filled in and only 29 of them were discarded due to incomplete answers. The data collected through the questionnaire were digitalized using a spreadsheet and submitted to descriptive statistics. Information about the brand and model of SS were not reported in the results of this study because they were used as a double-check to verify the reliability of farmer responses about the parameters recorded by their SS. None of the farmers included in the final data set responded to the open-ended questions placed at the end of sections 2 and 3 of the questionnaire.

\section{Performances of Dairy Herds Equipped or Not Equipped With Sensor Systems}

To understand the overall association between the presence of SS and the productive and reproductive performance of dairy herds, a subset of 100 dairy farms was selected from the survey database: half of them (n $=50$ ) were equipped with SS for monitoring at least individual milk yield and estrus (regardless of the type of 
SS) and the other half $(\mathrm{n}=50)$ were without any kind of SS. The selection of the subset of farms aimed at (1) creating a representative sample of the surveyed farm population according to the information gathered from the questionnaire on housing system, herd size, and cattle breed and (2) minimizing the overall farm effect on herd performances. Only farms with loose housing systems, similar herd size (ranging from 50-150 cows), and Holstein as the predominant breed type were selected $(\geq 75 \%$; Figure 1). Moreover, because the date of SS installation was not available, only farms for which the ARAV technicians reported that the SS status (having SS or not) had remained unchanged since the year 2014 were considered. Official test days of 3 yr (2015-2017) were then gathered from the ARAV database for each farm included in the subset. Data were collected at the herd level, and the number of test days available ranged from 10 to 12 per farm per year. The following traits were extrapolated and considered as the average of the data coming from 3 yr of test days: mature cow equivalent milk production (MEP), milk fat percentage, milk protein percentage, linear score of SCC (LS), age at first calving, calving interval, number of services per pregnancy, number of lactations, and percentage of culled cows. The MEP was already available in the official test days, whereas LS was calculated based on SCC $(\times 1,000$ cells $/ \mathrm{mL})$ as following: $\log _{2}(\mathrm{SCC} / 100)+$ 3 (Shook, 1993).

First, Spearman rank correlation analysis was performed to investigate the existing relations among the variables (SAS Institute Inc., Cary, NC). The ANOVA was then carried out by repeated mixed model (SAS PROC MIXED) to test the effect of the farm group (having SS or not) on the selected variables. The linear model included the fixed and repeated effect of the year $(2015,2016$, and 2017), the effects of the month and farm group, and the interaction between year and month and year and farm group. The farm effect (nested within the group) was included as a random and

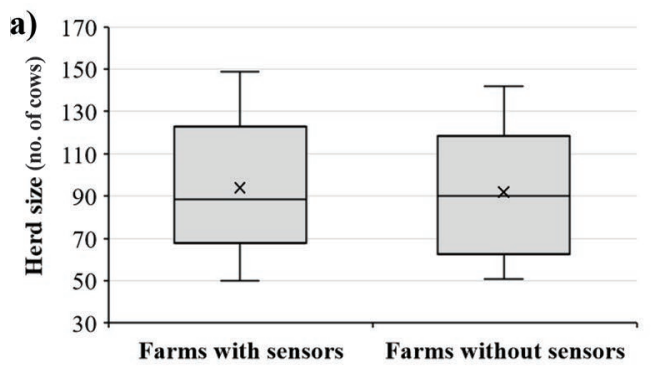

repeated factor. The hypotheses of the linear model were graphically assessed on the residuals.

Because several factors (in addition to those considered in farm selection) can affect herd performances and potentially hide an effect of using a SS, a second approach was adopted to further verify the association between the presence of SS and herd performances. Therefore, the same subsample of 100 farms was also submitted to a clustering analysis based on the same productive and reproductive variables used for the ANOVA. Clustering algorithms are generally used in an unsupervised fashion as exploratory data analysis. They comprehend a broad class of methods for discovering unknown subgroups among data. K-means clustering is an approach for partitioning a data set into $\mathrm{k}$ distinct, nonoverlapping clusters so that the items within each group are more similar to each other than the others included in different groups. The average herd productive and reproductive variables described above were used to cluster the 100 farms. K-means cluster analysis (PROC FASTCLUS) was run with 3, 4, 5, 6, and 7 clusters, setting 10 farms as the minimum size of the clusters. Leave-one-out cross-validation of the clustering criterion was conducted (SAS PROC DISCRIM) and the confusion matrix was generated. Reliability indexes (sensitivity, specificity, accuracy, precision, and Matthews correlation coefficient) were calculated as in Bisutti et al. (2019). Two main canonical variables (Can1 and Can2) were computed for plotting the clusters using canonical discriminant analysis (SAS PROC CANDISC) and total-sample correlations between the canonical variables and the original variables were calculated (canonical coefficients). The loadings of the 100 farms were drawn in the Can1 $\times$ Can2 Euclidean space. The effect of the clustering on the predictive variables was then tested by one-way ANOVA for normally distributed variables and by Kruskall Wallis test for not-normally distributed ones. Finally, the proportion of farms with SS within each cluster was calculated and

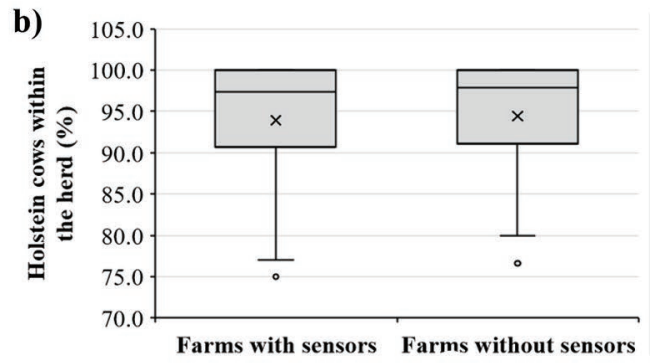

Figure 1. Box and whiskers plots showing (a) herd size and (b) percentage of Holstein cows within the herd of the subsets of 50 dairy farms equipped with sensor systems and 50 dairy farms without any sensor system selected in the study. Medians (horizontal lines), means ( $\times$ ), interquartile ranges (boxes), and 95th percentile (whiskers) are represented. Outliers are plotted separately as dots. 
बFarms (no.) $\square$ Sensors for both MY and ED (\%) $\square$ Sensors for MY (\%) $\square$ Sensors for ED (\%) $\square$ No sensor (\%)

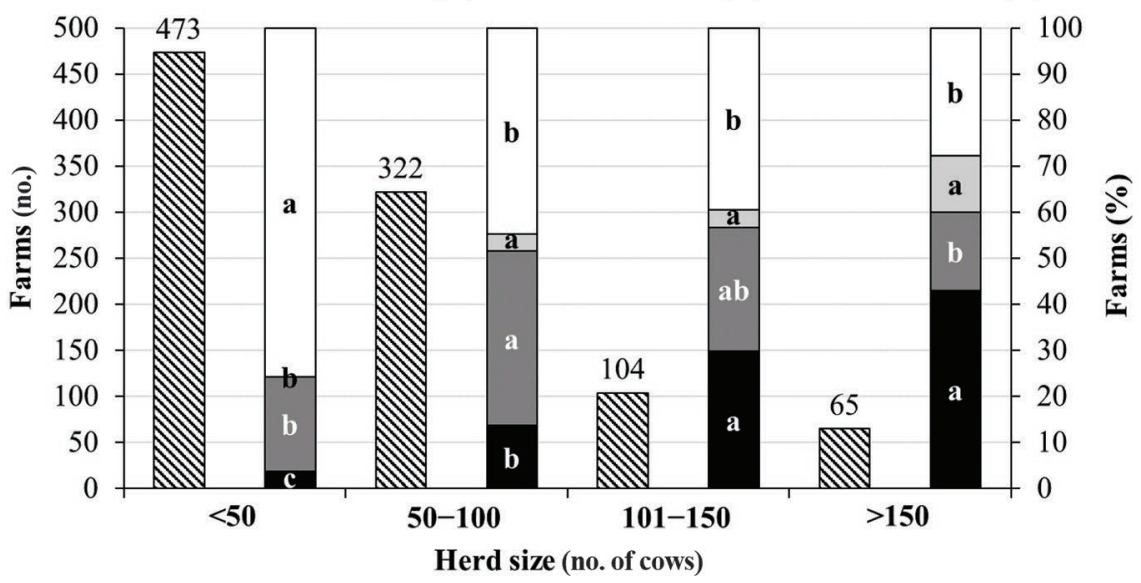

Figure 2. Distribution of the 964 surveyed Italian dairy farms according to the herd size, and proportion of farms equipped with sensor systems to monitor at least either individual cow milk yield (MY), estrus (ED), or both within classes of herd size. Variables of the same color with different letters $(\mathrm{a}, \mathrm{b})$ differ $(P<0.05)$.

compared by a Chi-squared test. The threshold level of statistical significance was set at $P<0.05$ for all the analyses performed.

\section{RESULTS AND DISCUSSION}

The Po Valley is the main dairy area of Italy, containing $90 \%$ of the 1.4 million dairy cows reared in the whole country (AIA, 2018). According to the official report of the local agency of the Italian breeders association, a total of 1,145 dairy farms and 99,741 dairy cows are kept under official control in the surveyed area, with an average herd size of 87 cows (AIA, 2018). The final data set included the responses from 964 dairy farms rearing more than 65,000 cows (Table 1), equal to $84 \%$ of the total number of dairy farms and $66 \%$ of the dairy cow population considered. Based on these outcomes, it was estimated that the small share

Table 1. Descriptive features of the surveyed sample of Italian dairy farms

\begin{tabular}{lc}
\hline Feature & Value \\
\hline Overall farms (n) & 964 \\
Overall cows reared (n) & 65,375 \\
Herd size (cows, n) & $68 \pm 66^{1}$ \\
Housing system (farms, \%) & 65.4 \\
Loose housing & 34.6 \\
Tiestall & \\
Breed type (overall cows, \%) & 72.2 \\
Holstein & 7.4 \\
Italian Brown & 5.8 \\
Simmental & 4.9 \\
Other pure- and local dual-purpose breeds & 9.7 \\
Crossbred & \\
\hline
\end{tabular}

${ }^{1}$ Mean \pm SD. of farms that did not take part in the survey had a larger average herd size (190 cows) compared with the average regional value.

The collaboration with the technicians in charge of the routine test days was a strength of this survey. Questionnaires were filled in during face-to-face interviews with the farmers, which allowed for the inclusion of farmers that were less familiar with online technology. Other authors encountered the "online format" strategy as a bias of their surveys, which almost precluded them from obtaining fully reliable data at the population level (Borchers and Bewley, 2015; Steeneveld and Hogeveen, 2015; Steeneveld et al., 2015).

The herd size of the surveyed farms ranged from 10 to 662 cows, with an average value (reported in Table 1) lower than the official regional one (AIA, 2018). Half of the surveyed farms (49\%) reared less than 50 cows, and $44 \%$ had a herd size ranging from 50 to 150 cows (Figure 2). Most of the cows reared in the surveyed farms belonged to the Holstein breed, whereas Italian Brown and Simmental cows accounted for less than $8 \%$ each (Table 1). Crossbreds were a relevant percentage of the surveyed cow population. These results are in line with the national statistics for the dairy cattle population, where Holstein is the predominant breed reared in Italy (over 1 million heads), followed by Italian Brown and Simmental (about 70,000 heads each; AIA, 2018).

Loose housing was the predominant housing solution (Table 1), with $57.9 \%$ of farms with a freestall system with cubicles and $7.5 \%$ with a deep littered resting area; the tiestall system was typical of small or medium-size farms ( $87 \%$ of these reared $<50$ cows). Only $3.7 \%$ of the freestall farms were equipped with AMS (Table 2), a fairly low proportion when compared with data 
Table 2. Proportion of the surveyed Italian dairy farms $(\mathrm{n}=964)$ that are equipped with sensor systems for monitoring milking-linked parameters and cow behavior by main types of sensors, and proportion of farms in which sensor systems are used to record various parameters

\begin{tabular}{lc}
\hline Item & $\begin{array}{c}\text { Farms percentage } \\
(\mathrm{n}=964)\end{array}$ \\
\hline Sensors at milking (overall) & 39.3 \\
Sensors in milking parlor & 31.9 \\
Automatic milking system & 3.7 \\
Sensors on milk pipeline & 3.7 \\
Sensors for cow behavior (overall) & 15.0 \\
Collars & 8.2 \\
Pedometers & 6.6 \\
Eartags & 0.2 \\
Parameters recorded by sensors ${ }^{1}$ & \\
Individual milk yield & 39.3 \\
Estrus & 15.0 \\
Mastitis event & 8.4 \\
Visit to the manger & 5.1 \\
Resting & 3.4 \\
Rumination & 3.4 \\
Milk fat and protein content & 2.2 \\
Cow location in the barn & 1.0 \\
\hline
\end{tabular}

${ }^{1}$ Surveyed farmers chose 1 or more parameters from a predetermined list of options.

from northern Europe (Barkema et al., 2015) where the frequency of AMS ranges from approximately 5\% (Germany) to 25\% (Denmark).

\section{Sensor System Availability on Italian Dairy Farms}

Overall, $41.8 \%$ of the surveyed dairy farms were equipped with at least $1 \mathrm{SS}$. This proportion was similar to that reported by Steeneveld and Hogeveen (2015) for Dutch dairy farms (39\%). Individual milk yield and estrus detection were the main information that farmers looked for from the SS (Table 2), which is in line with the previous findings from surveys on this topic (Borchers and Bewley, 2015; Steeneveld and Hogeveen, 2015). According to these studies, a favorable cost-tobenefit ratio is the main reason why a farmer would invest in a given SS, and improving herd milk yield, reproductive performance, and health are considered the most immediate ways to increase herd profitability.

Individual daily milk yield was also the most frequently measured parameter $(52 \%)$ in the 109 dairy farms surveyed by Borchers and Bewley (2015), but they found that data on mastitis detection and milk components (fat and protein content) were more frequently recorded (26\% and $25 \%$, respectively) compared with our findings (Table 2). Such a difference might arise from the greater proportion of AMS that are operating in US dairies. In fact, according to Steeneveld and Hogeveen (2015), SS for recording more sophisticated parameters are often present on-farm not because of a conscious choice of the farmers, but because they are an integrated part of AMS devices or provided as optional at an advantageous cost.

Data in Table 2 show that the proportion of herds equipped with automatic estrus detection devices was much lower than that of about $40 \%$ recorded both in the United States (Borchers and Bewley, 2015) and in the Netherlands (Steeneveld and Hogeveen, 2015). However, there are no historical data available to determine whether the adoption of this kind of SS in Italy is still at an early stage.

Additional parameters such as rumination, visit to the manger, or resting behavior were automatically recorded in less than $5 \%$ of the surveyed farms (Table 2). Sensor technologies able to record such parameters are relatively recent (Barkema et al., 2015), and farmers could be still reluctant to invest in them either because the outputs they get are not user-friendly or because they are overloaded by the amount of information that SS provide (Russell and Bewley, 2013; King and DeVries, 2018).

Consistent with the findings of Jackson-Smith and Barham (2000) about Wisconsin dairy farms, the results of our survey showed that the proportion of farms equipped with some SS tended to increase with the herd size (Figure 2). In our survey, $71.5 \%$ of the SS were installed on farms with more than 50 cows and approximately $60 \%$ of the dairy farms were equipped with at least 1 SS (Figure 2). Even the proportion of farms equipped with SS for monitoring both milk yield and estrus (overall $=12.6 \%$ ) increased with the herd size (Figure 2).

Considering the average herd size estimated for the farms that did not enter the study (190 cows), it could be hypothesized that the overall diffusion of SS in the surveyed area might have been slightly underestimated. According to the results of this study, we can state that dairy farmers need technological aid when the herd size is over a minimum threshold value, which is needed to justify their investment cost (Russell and Bewley, 2013; Borchers and Bewley, 2015). On farms with larger herds, the choice of introducing SS could be driven by the need to cover the increased demand for time and labor.

\section{Performances of Dairy Herds Equipped or Not Eqipped with Sensor Systems}

To understand whether the performance of similar herds can be influenced by the presence of SS on-farm, productive and reproductive data of 50 farms equipped with SS for monitoring at least milk yield and estrus were compared with those of another equal number of farms with similar characteristics but not equipped with any kind of SS. Spearman rank correlation analysis de- 
Table 3. ANOVA (LSM, SEM, and $P$-value) of productive and reproductive parameters of the subset of 100 Holstein dairy farms equipped or not equipped with sensor systems for monitoring at least individual cow milk yield and estrus

\begin{tabular}{|c|c|c|c|c|}
\hline \multirow[b]{2}{*}{ Item } & \multicolumn{2}{|c|}{ Farm } & \multirow[b]{2}{*}{ SEM } & \multirow[b]{2}{*}{$P$-value } \\
\hline & With sensors & Without sensors & & \\
\hline Farms (n) & 50 & 50 & & \\
\hline Mature-equivalent milk production (kg) & 11.074 & 10,486 & 188 & 0.030 \\
\hline Milk fat $(\%)$ & 3.76 & 3.75 & 0.03 & 0.783 \\
\hline Milk protein (\%) & 3.36 & 3.39 & 0.01 & 0.068 \\
\hline Linear score of SCC & 4.36 & 4.27 & 0.08 & 0.465 \\
\hline Age at first calving (mo) & 27.2 & 27.4 & 0.3 & 0.689 \\
\hline Calving interval (d) & 436 & 433 & 4 & 0.700 \\
\hline Services per pregnancy $(\mathrm{n})$ & 2.39 & 2.27 & 0.07 & 0.268 \\
\hline Number of lactations & 2.28 & 2.29 & 0.04 & 0.875 \\
\hline Cows culled $(\%)$ & 34.7 & 33.3 & 1.3 & 0.417 \\
\hline
\end{tabular}

tected a negative correlation between MEP and age at first calving $(-0.52 ; P<0.05)$ and between MEP and LS $(-0.52 ; P<0.05)$. The outcomes of the ANOVA showed that having or not having SS was not associated with different herd performances, with the only exception for MEP, which was higher in the group of farms equipped with SS $(P<0.05$; Table 3$)$. According to Steeneveld et al. (2015), who found similar results in a study on Dutch farms, it could be hypothesized that the positive effect on milk yield for the group of farms with SS could partially arise from the presence of farms equipped with AMS (approximately a third of the farms in the group), which is well-known to increase milk production because of the possibility of a higher milking frequency (Wagner-Storch and Palmer, 2003; De Marchi et al., 2017).

Because several factors that are difficult to control may influence dairy herd performances in addition to SS adoption, the same subset of 100 Holstein dairy farms was further analyzed by clustering analysis. Three clusters of farms with different productive and reproductive performances were identified $\left(R^{2}=0.80\right.$; Table 4). Cluster 3 was composed of the farms with the best performance in terms of MEP, LS, age at first calving, and calving interval, cluster 2 had intermediate values, and cluster 1 was the lowest in yield but had the best milk quality in terms of fat and protein content (Table 4). Clusters did not differ for the average number of services per pregnancy, number of lactations, and percentage of cows culled (Table 4).

The robustness of the cluster approach was confirmed both by the results of the cross-validation that showed a low percentage of misclassified observations and by the satisfactory values of the reliability indexes, always above $85 \%$ (Table 5). The canonical discriminant analysis showed a first canonical variable (Can1) that accounted for $98 \%$ of the total variability, and mainly correlated with MEP (0.98) and inversely

Table 4. Clusters of the subset of 100 Holstein dairy farms equipped $(\mathrm{n}=50)$ or not equipped $(\mathrm{n}=50)$ with sensor systems for monitoring at least individual cow milk yield and estrus, and differences of herd performances among clusters

\begin{tabular}{|c|c|c|c|c|c|}
\hline Item & \multicolumn{3}{|c|}{ Cluster $^{1}$} & Statistical test & $P$-value \\
\hline Mature-equivalent milk production $(\mathrm{kg})$ & $8,387 \pm 165^{\mathrm{c}}$ & $10,508 \pm 87^{\mathrm{b}}$ & $12,088 \pm 103^{\mathrm{a}}$ & $190^{2}$ & $<0.001$ \\
\hline Milk fat (\%) & $3.87(3.77-3.94)^{\mathrm{a}}$ & $3.72(3.66-3.87)^{\mathrm{b}}$ & $3.66(3.57-3.77)^{\mathrm{b}}$ & $13.96^{3}$ & $<0.001$ \\
\hline Milk protein (\%) & $3.42 \pm 0.02^{\mathrm{a}}$ & $3.39 \pm 0.01^{\mathrm{a}}$ & $3.34 \pm 0.01^{\mathrm{b}}$ & $5.35^{2}$ & 0.006 \\
\hline Linear score of SCC & $4.74 \pm 0.15^{\mathrm{a}}$ & $4.43 \pm 0.08^{\mathrm{a}}$ & $4.04 \pm 0.09^{\mathrm{b}}$ & $9.74^{2}$ & $<0.001$ \\
\hline Services per pregnancy (n) & $2.37 \pm 0.14$ & $2.22 \pm 0.07$ & $2.48 \pm 0.9$ & $2.66^{2}$ & 0.075 \\
\hline Number of lactations & $2.38 \pm 0.07$ & $2.27 \pm 0.04$ & $2.29 \pm 0.04$ & $1.06^{2}$ & 0.350 \\
\hline Cows culled (\%) & $33.2 \pm 2.2$ & $34.4 \pm 1.2$ & $33.6 \pm 1.4$ & $0.16^{2}$ & 0.855 \\
\hline
\end{tabular}

${ }^{\mathrm{a}-\mathrm{c}}$ Values within a row with different superscripts differ $(P<0.05)$.

${ }^{1}$ Data are reported as least squares means \pm standard error for normally distributed variables, and as median and interquartile range for notnormally distributed ones.

${ }^{2} F$-value (normally distributed data).

${ }^{3}$ Kruskall Wallis test (nonparametric data). 
a)

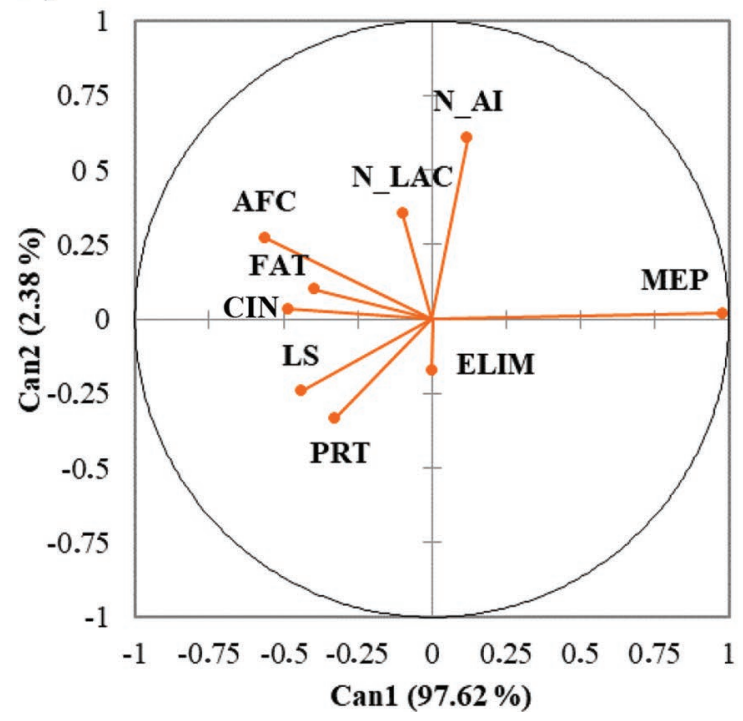

b)

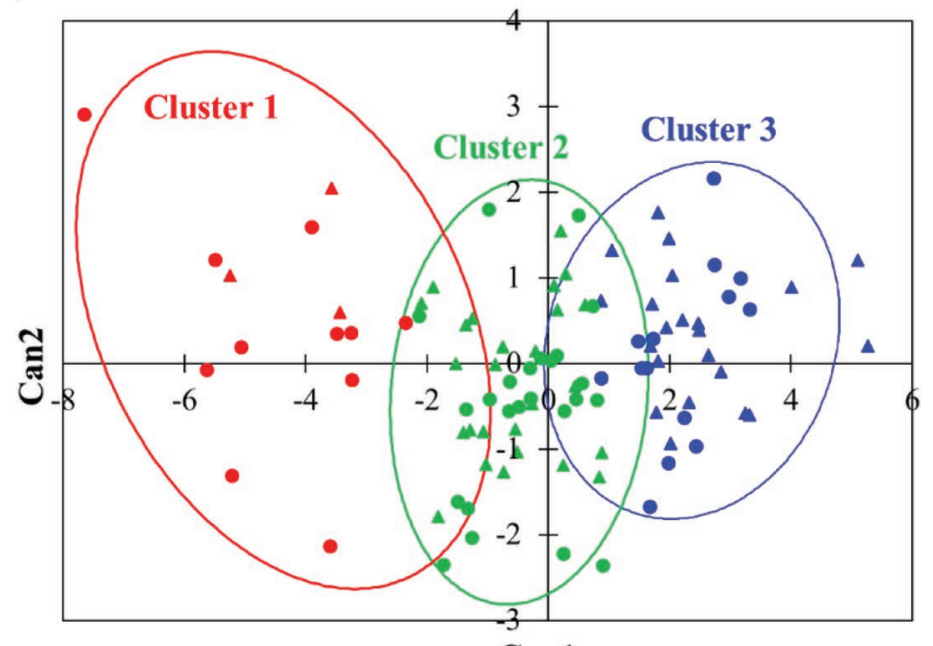

Figure 3. (a) Canonical coefficients between original variables and the 2 main canonical variables and (b) loadings of the subset of 100 Holstein dairy farms grouped by the clustering analysis according to the 2 canonical variables Can1 and Can2. Different loading symbols in the

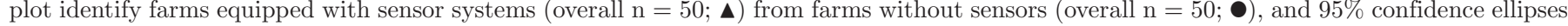
for each cluster are drawn (b). MEP = mature cow equivalent milk production; FAT = milk fat percentage; PRT = milk protein percentage; $\mathrm{LS}=$ linear score of SCC; $\mathrm{AFC}=$ age at first calving; CIN = calving interval; N_AI = number of services per pregnancy; $\mathrm{N} \_$LAC $=$number of lactations; ELIM = percentage of cows culled.

correlated with age at first calving $(-0.56)$, calving interval (-0.48), and LS (0.44; Figure 3a). The plot of the loadings of the 100 farms confirmed the diversity among clusters, and between cluster 1 and cluster 3 in particular (Figure 3b).

Moving to the right along the $\mathrm{x}$-axis of Figure 3b, the percentage of farms equipped with SS within each cluster increased, reaching its maximum in cluster 3. According to the results of the Chi-squared test, cluster 3 had the highest percentage of farms equipped with SS $(61 \%)$, cluster 2 had an intermediate value $(50 \%)$, and cluster 1 had the lowest percentage of farms with SS $(21 \% ; P<0.05 ;$ Figure 3b).
As previously discussed, the higher MEP found for cluster 3 and cluster 2 compared with cluster 1 could be explained by the presence of more farms equipped with AMS, whereas the opposite trend observed for fat and protein content was probably linked to the lower MEP of cluster 1 compared with cluster 3, rather than to an effect of the SS. It is common knowledge that constituents of milk concentration are negatively correlated with milk yield (Gaunt, 1980).

The lowest LS recorded in cluster 3 could be linked both to a positive effect of the SS adoption and to a general better level of management of these farms. More sophisticated SS are sometimes associated with

Table 5. Confusion matrix and descriptive statistics of clustering analysis cross-validation, performed for the subset of 100 Holstein dairy farms; number of farms (actual vs. predicted), misclassification rate, and indices of reliability are reported

\begin{tabular}{lccccc}
\hline & & \multicolumn{3}{c}{ Predicted cluster } & \\
\cline { 3 - 4 } Item & Farms(n) & 1 & 2 & 3 & Misclassification rate \\
\hline Actual cluster & & & & & \\
$\quad 1$ & 36 & 33 & 3 & 0 & $8.3 \%$ \\
2 & 50 & 1 & 47 & 2 & $6.0 \%$ \\
3 & 14 & 0 & 0 & 14 & $0.0 \%$ \\
Total & & 34 & 50 & 16 & $4.8 \%$ \\
Sensitivity & & 0.92 & 0.94 & 1.00 & \\
Specificity & & 0.98 & 0.94 & 0.98 & \\
Accuracy & & 0.96 & 0.94 & 0.98 & \\
Precision & & 0.97 & 0.94 & 0.88 & \\
Matthews correlation coefficient & & 0.91 & 0.88 & 0.92 & \\
\hline
\end{tabular}


milk yield-recording systems to allow real-time monitoring of milk quality and mastitis events (de Mol and Ouweltjes, 2001; Hogeveen et al., 2010; de Koning, 2011). In the case of AMS, however, a positive effect on LS should be considered carefully, as the AMS adoption has been more frequently linked to a higher SCC compared with similar farms without AMS or with the same farm before the AMS adoption (Kruip et al., 2002; Steeneveld et al., 2015).

The better reproductive performance in terms of calving interval of cluster 3 compared with the other clusters can be linked to the adoption of SS. Gaude et al. (2017) reported that SS can improve estrus detection by $30 \%$ compared with visual detection performed by the herdsman. From an economic point of view, van Asseldonk et al. (1999) estimated an advantage of 0.57 $€$ per $100 \mathrm{~kg}$ of fat- and protein-corrected milk for an improvement of estrous detection of $40 \%$ in an average Dutch dairy herd, whereas Rutten et al. (2014) estimated a baseline advantage of about 2,800 € for installing a SS for estrus detection, due to better cow reproductive performances (shorter calving interval, higher milk production per cow per year).

The average lower age at first calving of cluster 3 and cluster 2 compared with cluster 1 could be due to an overall better fertility management of farms of these clusters, but we cannot exclude that some farms in cluster 3 and cluster 2 had installed SS for estrus detection, also on the heifer group, thus helping improve the age at first calving. However, this aspect should be further investigated, as a previous study did not observe a clear positive effect of providing the heifer group with devices for estrus detection on age at first calving (Steeneveld et al., 2015).

Finally, it must be noted that $40 \%$ of farms allocated into cluster 3 were not equipped with SS and, on the other hand, some farms equipped with SS were allocated into cluster 1 . This suggests that the adoption of SS should not necessarily be associated with better herd performance and that skilled herd and SS information management is essential. Moreover, the choice of investing in SS might not be driven only by their potential benefits on herd performance, as farmers may invest in SS to partially cover other specific needs such as the demand for time and labor for herd management, as discussed above.

\section{CONCLUSIONS}

The survey carried out in this study showed that $41.8 \%$ of the 964 Italian dairy farms covered were equipped with at least 1 SS. Sensor technology was implemented mainly on farms with more than 50 cows, and SS to measure individual cow milk yield were the most prevalent $(39.3 \%)$, followed by devices for estrus detection (15.0\%). More advanced and expensive SS, able to record cow rumination, feeding, or resting behavior, were found in a small percentage of farms $(\leq 5 \%)$, thus showing that Italian dairy farmers still hesitate to invest in monitoring more sophisticated parameters. The assessment of the association between SS adoption and herd performance on a subset of 100 Holstein farms only showed that farms with SS had higher mature-equivalent milk production. Clustering analysis of the same 100 farms partitioned them into 3 clusters based on herd productive and reproductive data. Despite the greater proportion of SS farms assigned to the cluster with the best performances, the presence of a few SS farms in the worst cluster for the same parameters pointed out that the mere installation of SS is not a guarantee of better herd performances. Other factors, such as skilled technical and managerial knowledge of the herdsman, still play a fundamental role in the success of the herd.

\section{ACKNOWLEDGMENTS}

The authors wish to acknowledge the breeders association of the Veneto Region (ARAV), and especially their technicians, for carrying out the survey and providing the data. This research was supported by a grant of the European project GenTORE (Horizon 2020 Research and Innovation Program, grant agreement no. 727213). The authors declare no conflict of interest.

\section{REFERENCES}

AIA (Italian Animal Breeders Association). 2018. On-line Bulletin. Accessed August 2019. http://bollettino.aia.it/.

Bar, D., and R. Solomon. 2010. Rumination collars: What can they tell us. Pages 214-215 in proceedings of the First North American Conference on Precision Dairy Management, Toronto, Canada. University of Toronto Press, Toronto, Canada.

Barkema, H. W., M. A. G. von Keyserlingk, J. P. Kastelic, T. J. G. M. Lam, C. Luby, J.-P. Roy, S. J. LeBlanc, G. P. Keefe, and D. F. Kelton. 2015. Invited review: Changes in the dairy industry affecting dairy cattle health and welfare. J. Dairy Sci. 98:7426-7445. https://doi.org/10.3168/jds.2015-9377.

Bisutti, V., R. Merlanti, L. Serva, L. Lucatello, M. Mirisola, S. Balzan, S. Tenti, F. Fontana, G. Trevisan, L. Montanucci, B. Contiero, S. Segato, and F. Capolongo. 2019. Multivariate and machine learning approaches for honey botanical origin authentication using near infrared spectroscopy. J. Near Infrared Spectrosc. 27:65-74. https://doi.org/10.1177/0967033518824765.

Borchers, M. R., and J. M. Bewley. 2015. An assessment of producer precision dairy farming technology use, prepurchase considerations, and usefulness. J. Dairy Sci. 98:4198-4205. https://doi .org/10.3168/jds.2014-8963.

de Koning, C. J. A. M. 2010. Automatic milking - Common practice on dairy farms. Pages 52-67 in Proceedings of the First North American Conference on Precision Dairy Management, Toronto, Canada. University of Toronto Press, Toronto, Canada.

de Koning, C. J. A. M. 2011. Milking machines: Robotic milking. Pages 925-958 in Encyclopedia of Dairy Science. J. W. Fuquay, ed. Academic Press, San Diego, CA. 
De Marchi, M., M. Penasa, and M. Cassandro. 2017. Comparison between automatic and conventional milking systems for milk coagulation properties and fatty acid composition in commercial dairy herds. Ital. J. Anim. Sci. 16:363-370. https://doi.org/10.1080/ 1828051X.2017.1292412.

de Mol, R. M., and W. Ouweltjes. 2001. Detection model for mastitis in cows milked in an automatic milking system. Prev. Vet. Med. 49:71-82. https://doi.org/10.1016/S0167-5877(01)00176-3.

Gaude, I., A. Kempf, K. D. Strüve, and M. Hoedemaker. 2017. Comparison of visual and computerized estrous detection and evaluation of influencing factors. Anim. Reprod. Sci. 184:211-217. https: //doi.org/10.1016/j.anireprosci.2017.07.019.

Gaunt, S. N. 1980. Genetic variation in the yields and contents of milk constituents. Bull. Int. Dairy Fed. 125:73-82.

Hogeveen, H., C. Kamphuis, W. Steeneveld, and H. Mollenhorst. 2010. Sensors and clinical mastitis-The quest for the perfect alert. Sensors (Basel) 10:7991-8009. https://doi.org/10.3390/s100907991.

Jackson-Smith, D. B., and B. Barham. 2000. The changing face of Wisconsin dairy farms: A summary of PATS' research on structural change in the 1990s. Vol. 7. Program on Agricultural Technology Studies, College of Agricultural and Life Sciences, University of Wisconsin-Madison.

King, M. T. M., and T. J. DeVries. 2018. Graduate student literature review: Detecting health disorders using data from automatic milking systems and associated technologies. J. Dairy Sci. 101:8605-8614. https://doi.org/10.3168/jds.2018-14521.

Kruip, T. A. M., H. Morice, M. Robert, and W. Ouweltjes. 2002. Robotic milking and its effect on fertility and cell counts. J. Dairy Sci. 85:2576-2581. https://doi.org/10.3168/jds.S0022-0302(02)74341 -5 .

Mottram, T. 2016. Animal board invited review: Precision livestock farming for dairy cows with a focus on oestrus detection. Animal 10:1575-1584. https://doi.org/10.1017/S1751731115002517.

Ouweltjes, W., Y. de Haas, and C. Kamphuis. 2019. At-market sensor technologies to develop proxies for resilience and efficiency in dairy cows. Pages 246-253 in Proc. 9th European Conference on Precision Livestock Farming, ECPLF 2019, Cork, Ireland. B. O'Brien, D. Hennessy, and L. Shalloo, ed. Teagasc, Ireland.

Russell, R. A., and J. M. Bewley. 2013. Characterization of Kentucky dairy producer decision-making behavior. J. Dairy Sci. 96:47514758. https://doi.org/10.3168/jds.2012-6538.

Rutten, C. J., W. Steeneveld, C. Inchaisri, and H. Hogeveen. 2014. An ex ante analysis on the use of activity meters for automated estrus detection: To invest or not to invest? J. Dairy Sci. 97:6869-6887. https://doi.org/10.3168/jds.2014-7948.

Rutten, C. J., A. G. J. Velthuis, W. Steeneveld, and H. Hogeveen. 2013. Invited review: Sensors to support health management on dairy farms. J. Dairy Sci. 96:1928-1952. https://doi.org/10.3168/ jds.2012-6107.

Saint-Dizier, M., and S. Chastant-Maillard. 2012. Towards an automated detection of oestrus in dairy cattle. Reprod. Domest. Anim. 47:1056-1061. https://doi.org/10.1111/j.1439-0531.2011.01971.x.

Shook, G. E. 1993. Genetic improvement of mastitis through selection on somatic cell count. Vet. Clin. North Am. Food Anim. Pract. 9:563-581. https://doi.org/10.1016/S0749-0720(15)30622-8.
Stangaferro, M. L., R. Wijma, L. S. Caixeta, M. A. Al-Abri, and J. O. Giordano. 2016a. Use of rumination and activity monitoring for the identification of dairy cows with health disorders: Part I. Metabolic and digestive disorders. J. Dairy Sci. 99:7395-7410. https:// doi.org/10.3168/jds.2016-10907.

Stangaferro, M. L., R. Wijma, L. S. Caixeta, M. A. Al-Abri, and J. O. Giordano. 2016b. Use of rumination and activity monitoring for the identification of dairy cows with health disorders: Part II. Mastitis. J. Dairy Sci. 99:7411-7421. https://doi.org/10.3168/jds .2016-10908.

Stangaferro, M. L., R. Wijma, L. S. Caixeta, M. A. Al-Abri, and J. O. Giordano. 2016c. Use of rumination and activity monitoring for the identification of dairy cows with health disorders: Part III. Metritis. J. Dairy Sci. 99:7422-7433. https://doi.org/10.3168/jds .2016-11352.

Steeneveld, W., and H. Hogeveen. 2015. Characterization of Dutch dairy farms using sensor systems for cow management. J. Dairy Sci. 98:709-717. https://doi.org/10.3168/jds.2014-8595.

Steeneveld, W., J. C. M. Vernooij, and H. Hogeveen. 2015. Effect of sensor systems for cow management on milk production, somatic cell count, and reproduction. J. Dairy Sci. 98:3896-3905. https:// doi.org/10.3168/jds.2014-9101.

Steensels, M., A. Antler, C. Bahr, D. Berckmans, E. Maltz, and I. Halachmi. 2016. A decision-tree model to detect post-calving diseases based on rumination, activity, milk yield, BW and voluntary visits to the milking robot. Animal 10:1493-1500. https://doi.org/ 10.1017/S1751731116000744.

van Asseldonk, M. A. P. M., A. W. Jalvingh, R. B. M. Huirne, and A. A. Dijkhuizen. 1999. Potential economic benefits from changes in management via information technology applications on Dutch dairy farms: A simulation study. Livest. Prod. Sci. 60:33-44. https: //doi.org/10.1016/S0301-6226(99)00039-1.

van der Tol, R., and A. van der Kamp. 2010. Time series analysis of live weight as health indicator. Pages 230-231 in Proceedings of the First North American Conference on Precision Dairy Management, Toronto, Canada. University of Toronto Press, Toronto, Canada.

Wagner-Storch, A. M., and R. W. Palmer. 2003. Feeding behavior, milking behavior, and milk yields of cows milked in a parlor versus an automatic milking system. J. Dairy Sci. 86:1494-1502. https:// doi.org/10.3168/jds.S0022-0302(03)73735-7.

\section{ORCIDS}

I. Lora (1) https://orcid.org/0000-0001-8725-8597

F. Gottardo (1) https://orcid.org/0000-0002-0427-2180

B. Contiero () https://orcid.org/0000-0002-6586-5035

M. Cassandro @ https://orcid.org/0000-0002-8709-2870

G. Cozzi ๑ https://orcid.org/0000-0003-0408-1082 